\title{
INVENTORY CONTROL SYSTEMS FOR NUCLEAR POWERED CLOSED-CYCLE GAS TURBINE: TECHNICAL STUDIES ON EFFECT OF WORKING FLUID OPTIONS
}

\author{
Emmanuel O. Osigwe \\ Cranfield University \\ Cranfield, Bedfordshire, United Kingdom
}

\author{
Arnold Gad-Briggs \\ Cranfield University \& EGB Engineering \\ United Kingdom
}

\author{
Pericles Pilidis \\ Cranfield University \\ Cranfield, Bedfordshire, United \\ Kingdom
}

\author{
Theoklis Nikolaidis \\ Cranfield University \\ Cranfield, Bedfordshire, United \\ Kingdom
}

\author{
Suresh Sampath \\ Cranfield University \\ Cranfield, Bedfordshire, United \\ Kingdom
}

Keywords: Closed-Cycle Gas Turbine, Cycle Performance, Inventory Control System, Simulation, Generation IV Nuclear Reactor.

\begin{abstract}
The Inventory Control System (ICS) offer unique characteristics when modulating the gas turbine output power to match the required load demand. The unique opportunities it offers have made it to be widely used in most nuclear powered closed-cycle gas turbine plant design and operations. This paper presents a technical study on how the different working fluid options affect the design and performance characteristics of the inventory control system. The results from this study shows that using helium as cycle working fluid offers an advantage in terms of Reynolds effect on cycle efficiency and also enable the design for compact inventory tank size and weight which could have a direct effect on the capital cost, due to its thermodynamic characteristics. However, the long term operational cost of helium compared with other working fluid utilized in this study provides a reasonable argument to justify any investment decision.
\end{abstract}

\section{INTRODUCTION}

Despite its controversial reputation, the nuclear energy system has been widely recognized to play an important role in mitigating the increasing world clean energy demand (Abram and Ion 2008; Osigwe, Gad-Briggs, Nikoliadis, et al. 2018). Currently there are over 400 units of nuclear energy systems already built and operated around the world, and so many under development (Osigwe, Gad-Briggs, Nikoliadis, et al. 2018; Kelly 2014; Locatelli, Mancini, and Todeschini 2013). The nuclear energy system consists of the nuclear reactors, the fuel cycle technology, the energy conversion system (Rankine or Brayton Cycle) and the control systems. To this extent, there has been on-going research across the globe on the improvement of design, control and performance for the next generation of nuclear energy system technologies, with most publications focusing on the nuclear reactors, and the fuel cycle technology (Osigwe, Gad-Briggs, Nikolaidis, et al. 2018; Forum Generation IV International 2014). However, in the last few years, there has been considerable growing interest in the use of closed-cycle gas turbine technology for energy conversion of the Generation IV (Gen IV) nuclear reactors due to (Olumayegun, Wang, and Kelsall 2016; Frutschi 2005; Osigwe 2018; Decher 1994): (a) its easy adaptability (b) flexibility to changes in working fluid (c) high efficiency of electricity generation at part load (d) high level of availability and low maintenance cost. Importantly, the closed-cycle gas turbine could also provide potential savings in operating cost due to its ability to relatively maintain high performance efficiency under varying operating conditions, when compared with other advanced cycles (Frutschi 2005). This advantage can be achieved by implementing appropriate control strategy during the operation of the power plant.

There are different control options that are applicable to the successful operation of the closed-cycle gas turbine power plant which have been documented in references (Bammert and Krey 1971; Covert, Krase, and Morse 1974; Botha and Rousseau 2007; Osigwe 2018). The goal of these control options when implemented in closed-cycle gas turbine would be (a) for the power plant to quickly adjust to wide range of fluctuating load variation without significantly affecting the cycle thermal efficiency (b) for prevention of thermal shocks on plant components during critical transients, and (c) for providing automatic control maneuvers during plant start up and shut down and (d) for operational stability of the plant to avoid eventualities. 
To this end, among the various control options mentioned in the cited references (Bammert and Krey 1971; Covert, Krase, and Morse 1974; Botha and Rousseau 2007; Osigwe 2018), the inventory control system provide distinct characteristics when modulating the gas turbine power output to match the required energy or load demand from the grid. It has the capability to operate at high part-load efficiency over a wide operating range compared with other control options (Covert, Krase, and Morse 1974; Decher 1994; Frutschi 2005; Botha and Rousseau 2007). Consequently, great number of researches available in the public domain have focused on the use of inventory control systems in terms of cycle performance for load-following based on the energy mix in the electricity grid as maybe required by the regulators (Locatelli et al. 2015; Singh, Kearney, and Manzie 2013; Albright et al. 2017; Gad-Briggs, Pilidis, and Nikolaidis 2017; Munoz de Escalona et al. 2013). In reference (Matimba, Krueger, and Mathews 2007), the authors described how part-load operation using inventory control system can be achieved with multiple tank storage by extracting the working fluid from the main gas turbine loop into the storage tanks. Similarly, reference (Bitsch and Chaboseau 1970) analyzed the relationship between inventory control range, total control volume and total helium inventory in the helium coolant circuit during part-load operation. Also, in the different works of references (Nieuwoudt 2003; Berchtold and Keller 1962), the technical design for ICS and its performance have been described.

Exploring the potential that closed-cycle gas turbine offers in the use of different working fluid, it seems there is no up-to-date assessment on the effect of the different working fluid options in the design and performance of the ICS. Hence, the purpose of this paper is to present a technical study that compares the effect of helium, carbon dioxide, nitrogen, and air on the size, weight and cycle performance of the ICS for a Gen-IV nuclear powered closed-cycle gas turbine during part-load operation. However, it is important to mention that the choice of working fluid for the proposed Gen IV system is dictated by availability, material compatibility, and thermal stability (El-genk and Tournier 2009; Lee, J. Campbell, and Wright 1981; Robinson 1957).

The Gen-IV systems applicable to this analysis are the Very High-Temperature Reactors (VHTR) and Gas-cooled Fast Reactors (GFR). Both reactors are high-temperature helium cooled, with core outlet temperatures between $750^{\circ} \mathrm{C}$ $(1023 \mathrm{~K})$ and $950^{\circ} \mathrm{C}(1223 \mathrm{~K})$. The GFRs uses a fast-spectrum core, while the VHTRs utilize graphite moderation in the solid state. The benefits of using helium as cooling agent include chemical inertness, single phase cooling and neutronic transparency (Wang and Gu 2005; El-genk and Tournier 2009). However, the use of other working fluids and mixtures for reactor cooling such as carbon dioxide, nitrogen, argon have been proposed in different studies (Invernizzi 2017; Osigwe, Gad-Briggs, Nikoliadis, et al. 2018; Ulizar Alvarez. 1998). In addition, there are planned and on-going developmental projects for GFR and VHTR. These projects relate to testing of basic concepts and performance phase validation.

This analysis is demonstrated using thermodynamic and empirical relations implemented in GT-ACYSS; a performance and preliminary design code developed by the authors for closed-cycle gas turbine simulations (Osigwe et al. 2017). The results from this study show that using helium as cycle working fluid offers an advantage in terms of Reynolds effect on cycle efficiency and also enable the design for compact inventory tank size and weight which could have a direct effect on the capital cost, due to its thermodynamic characteristics. However, the long term operational cost of helium compared with other working fluid utilized in this study provides a reasonable argument to justify any investment decision.

\section{BASIC CONCEPT OF THE INVENTORY CONTROL SYSTEM}

As previously highlighted, the inventory control system has been widely mentioned as an attractive possibility (Gad-Briggs, Pilidis, and Nikolaidis 2017) because it allows the power plant to operate within wide range of load fluctuation at a good cycle thermal efficiency. The operating concept of the control logic is for the power plant to be able to store, or save energy during off-peak periods and replenish this energy during peak load demand via inventory control system (ICS). This means that the working fluid is either extracted or injected into the power conversion system, resulting in a related change in system pressure, change in density, change in mass flow rate and, therefore, also a change in power level.

During the plant operations, the daily fluctuations in power demand as a result of varying operating conditions are adjusted by means of the inventory control system (ICS), which comprises of the inventory control tank (ICT), and inventory control valves (ICV) as shown in Fig. 1. When reduction of shaft power is required as result of decrease in load demand, the ICV1 is opened so that the working fluid flows from the HPC into the ICT. The working fluid stored in the ICT(s) can be injected back into the power conversion circuit by opening of ICV3, and ICV6, if the output power is to be increased to full capacity. When inventory control is initiated, the heat source temperature and shaft speed are controlled to remain constant.

Figure 2 shows the iteration modelling procedure using inventory control at steady state condition. The iteration process starts with an initial guess of the turbine mass flow required to meet the part load demand. The inventory control system is regulated based on the pressure variation between the plant cycle and the inventory tank. This variation determines the power limit and possibility of maintaining high part-load efficiency to which inventory control is achieved. However, there are restrictions to the extent the inventory control system can maintain a high part load efficiency, which include (Osigwe, Pilidis, et al. 2018): (a) size and pressure of the inventory storage tank, (b) shaft rotational speed effect on blade tips (c) location of inventory valves in the cycle loop (d) availability of inventory transfer compressor, and (e) cost of implementing any of the options listed.

\section{METHOD OF ANALYSIS AND EQUATION}

The overall performance of the power plant is a function the constituent components of the Generation IV nuclear 
power plant; hence, the authors have given an overview of the thermodynamic equations implemented in GT-ACYSS for the overall performance assessment of the closed-cycle utilized in the case study, which is described as follow:

Turbo-set: This includes the compressor and the turbine. The behavior of the turbo-set is described with dimensionless parameters such as corrected mass flow, corrected speed, pressure ratio, component efficiencies and work functions. These parameters are plotted on graphs with lines of pressure ratio against corrected mass flow for different corrected speed lines and contour lines of constant efficiency. It is essential when expressing these parameters that the properties of the working fluid are taken into consideration, which is expressed as:

$$
C M F=\left(\frac{W \sqrt{\theta}}{\delta} \times \sqrt{\frac{R}{\gamma}}\right), C S=\left(\frac{N}{\sqrt{\theta R \gamma}}\right), C H=\left(\frac{\Delta H}{\sqrt{\theta R \gamma}}\right)
$$

Where,

$$
\theta=\frac{T}{T_{r e f}}, \text { and } \delta=\frac{P}{P_{r e f}}
$$

The compressor exit temperature is given by the expression

$$
T c_{\text {out }}=T c_{\text {in }}+\frac{T c_{\text {in }}}{\eta_{c}}\left[\left(\frac{P c_{\text {out }}}{P c_{\text {in }}}\right)^{\left(\frac{\gamma-1}{\gamma}\right)}-1\right]
$$

The compressor exit pressure is derived from the given pressure ratio as:

$$
P R_{c}=\frac{P c_{\text {out }}}{P c_{\text {in }}}=f(C M F, C S)
$$

The compressor work (CW), is a product of the mass flow, specific heat capacity at constant pressure and the overall temperature rise in the compressor. This is given as:

$$
C W=W C p\left(T c_{\text {out }}-T c_{\text {in }}\right)
$$

Similarly, turbine exit temperature is given by:

$$
T t_{\text {out }}=T t_{\text {in }}-T t_{\text {in }} \eta_{t}\left[1-\left(\frac{P t_{\text {out }}}{P t_{\text {in }}}\right)^{\left(\frac{\gamma-1}{\gamma}\right)}\right]
$$

And turbine work is expressed as:

$$
T W=W C p\left(T t_{\text {out }}-T t_{\text {in }}\right)
$$

The turbine discharge pressure ratio is calculated using Eq (7)

$$
P R_{t}=\frac{P t_{\text {out }}}{P t_{\text {in }}}=P R_{c}\left[\frac{\sum(1-\Delta P)_{H P S}}{\sum(1+\Delta P)_{L P S}}\right]
$$

Heat Exchangers: The heat exchangers which include the recuperator, gas heater and pre-cooler were modeled using the $\varepsilon$-NTU method and a counter-flow shell and tube configuration was assumed. The $\varepsilon-\mathrm{NTU}$ method was used since the inlet condition (temperature and pressure) of the fluid stream can be easily obtained and simplifies the iteration involved in predicting the performance of the flow arrangement. This method is fully described in references
(Shah and Sekulic 2003; Kakac and Liu 2002). The approach also assumes that the heat exchanger effectiveness is known and the pressure losses are given.

Therefore, the effectiveness of the heat exchanger is the ratio of the actual heat transfer rate to the thermodynamically limited maximum heat transfer rate available in a counter flow arrangement.

$$
\begin{gathered}
\varepsilon=\frac{Q_{\text {actual }}}{Q_{\max }} \\
=\frac{C_{\text {hot }}\left(T_{\text {hotin }}-T_{\text {hotout }}\right)}{C_{\text {min }}\left(T_{\text {hotin }}-T_{\text {coldin }}\right)} \\
=\frac{C_{\text {cold }}\left(T_{\text {coldout }}-T_{\text {coldin }}\right)}{C_{\text {min }}\left(T_{\text {hotin }}-T_{\text {coldin }}\right)}
\end{gathered}
$$

Where,

$$
\begin{gathered}
C_{\text {min }}=\left\{\begin{array}{l}
C_{\text {hot }} \text { for } C_{\text {hot }}<C_{\text {cold }} \\
C_{\text {cold }} \text { for } C_{\text {cold }}<C_{\text {hot }}
\end{array}\right. \\
C_{\text {hot }}=\left(W C_{P}\right) \text { hot fluid Stream } \\
C_{\text {cold }}=\left(W C_{P}\right) \text { cold fluid Stream }
\end{gathered}
$$

For counter flow shell and tube heat exchangers, number of transfer unit (NTU) is given by:

$$
N T U=\frac{L O G_{e}\left[\frac{2-\varepsilon\left(1+C^{*}-\eta_{\text {Hex }}\right.}{2-\varepsilon\left(1+C^{*}+\eta_{\text {Hex }}\right.}\right]}{\eta_{\text {Hеx }}}
$$

Where,

$$
C^{*}=\text { Capacity rate ratio }=\frac{C_{\min }}{C_{\max }}
$$

$$
\eta_{\text {Hex }}=\left(C^{* 2}+1\right)^{0.5}
$$

The inlet and out pressures of the heat exchangers were calculated from the relative pressure losses given by

$$
P_{\text {out }}=P_{\text {in }}(1-\Delta P)
$$

Reactor Model: The reactor was modeled as a heat source supplying reactor thermal power at a specified temperature and efficiency. The heat gained is given by:

$$
Q_{g}=W C_{p(\text { gas })} \Delta T
$$

The heat source pressure loss is calculated in a similar way as shown in Eq. (14). The power plant thermodynamic states of temperature and pressure at all components were obtained by solving Eqs. (1) - (15)

Cycle Performance Calculation: The overall plant cycle assessment is represented as shaft output power (SOP), specific output power (SP), and cycle thermal efficiency. These are given by the following equations:

$$
S O P=T W-C W / \eta_{m}
$$

The capacity of the plant is represented as specific power (SP), given by: 


$$
S P=S O P / W
$$

The cycle thermal efficiency is given by:

$$
\eta_{t h}=S O P / Q_{g}
$$

Next is the present the operating model for the inventory control system. As previously mentioned, the inventory control system consists of the inventory control tank (ICT), piping and valve fittings (ICV). Equations (19) - (45) presents the basic models implemented in GT-ACYSS for the assessment and comparison of the effect of carbon dioxide, helium, nitrogen and air in the performance and size of the ICS.

\section{Inventory Load Control Model:}

This model is implemented to assess the minimum and the maximum power range the ICS can handle during working fluid extraction and injection into the closed-cycle gas turbine loop based on the fluid properties for a given load demand from the grid. This was derived from a modified model of reference (Bitsch and Chaboseau 1970). Thus,

Minimum equilibrium inventory - control power range is given as

$$
\Omega_{\text {min }}=\frac{1+\frac{M_{T 1}}{M_{G T 5}}}{1+\psi\left(\frac{M_{T 1}}{M_{G T 5}}\right)}
$$

For multi ICT option, where $\mathrm{n}>1$, then

$$
\Omega_{\min }=\Omega_{\min } \frac{1}{n}
$$

The maximum equilibrium inventory - control power range is given by

$$
\Omega_{\max }=\frac{1+\frac{M_{T 1}}{M_{G T 5}}}{1+\left(\frac{\psi}{O P R}\right)\left(\frac{M_{T 1}}{M_{G T 5}}\right)}
$$

Where

$$
\begin{gathered}
\psi=\frac{P_{5}}{P_{T 1}} \\
n=\text { number of storage tank } \\
O P R=\text { overall cycle pressure ratio }
\end{gathered}
$$

\section{Thermo-fluid model}

To model the thermodynamic behaviour of the plant utilising inventory control, the law of conservation of mass, conservation of momentum and conservation of energy was used to balance the fluid extraction and injection in the GT-cycle and storage tank relationship (Matimba, Krueger, and Mathews 2007).

$$
\Delta M_{T}=\Delta M_{G T}
$$

Where,

$$
\Delta M_{T}=\frac{\Delta P_{T} \times V_{T}}{R T_{t}}=\frac{\Delta P_{G T} \times V_{G T}}{R T_{G T}}=\Delta M_{G T}
$$

Energy balance is given by

$$
\begin{gathered}
\delta Q-\delta W=\delta U+\delta P E+\delta K E \\
\delta W=0, \delta K E=0, \delta P E=0
\end{gathered}
$$

Since the storage tank is a stationary closed system and no boundary work is done, it means that $\delta K E=\delta P E=0$. Where, KE is the kinetic energy and PE potential energy.

\section{Storage Tank and GT-cycle loop}

During low power demand (part-load operation), the ICV1 is opened for extraction of working fluid into the inventory tanks, the HPC discharge temperature remain constant during the extraction process. This is so because the heat supplied from the reactor is kept constant, hence the temperature across the gas turbine gas path remains constant and the large variation of the HPC temperature to the storage tank initial temperature. Similarly during the injection into the GT-cycle loop, the reverse was the case with opening of the ICV3 and ICV6.

Assuming the inventory tank is design such that there is a slow in change temperature throughout the extraction process from the gas turbine HPC discharge into the ICT. This is achieved by intermittently transferring the working fluid into the ICT, such that the ICT is allowed to cool by some degree before further extraction. Then equations (26) and (27) can be used to obtain the total mass and volume of the ICT.

$$
\Delta M_{T}=\left(1-\Omega_{\min }\right) \times M_{G T 5}
$$

$$
V_{T}=\left[\frac{\left(1-\Omega_{\min }\right) \times M_{G T 5} \times R T_{t}}{\left(P_{t 2}-P_{t 1}\right)}\right]
$$

However, in reality there is variation in temperature of the inventory tank as a result of rapid heat and mass transfer from the gas turbine HPC discharge temperature during the extraction process. Therefore, the total volume of gas in the ICT is obtained as follows;

$$
V_{T}=\left[\frac{\left(1-\Omega_{\min }\right) \times M_{G T 5} \times\left(R T_{t 2}-R T_{t 1}\right)}{\left(P_{t 2}-P_{t 1}\right)}\right]
$$

From equation (27) and (28) the tank final temperature is calculated as

$$
T_{t 2}=\left[\frac{T_{t 1} C_{v} M_{T 1}+C_{p G T}\left(\Delta M_{G T}\right) T_{G T}}{C_{v} M_{T 2}}\right]
$$

To minimise the effect of heat transfer into the storage tank, perforated insulation is implemented on the internal of the storage tank to absorb the heat from the GT-Cycle loop fluid, thus lowering the tank temperature and consequently the pressure build-up allowing more fluid to be stored. Hence, the ICT final temperature is given as;

$$
T_{t 2}=T_{\text {cap }}+\Delta T_{\text {lag }}
$$

Where $T_{\text {cap }}$ is the temperature of insulation and $\Delta T_{\text {lag }}$ is the temperature difference between the cycle working fluid flowing to storage tank and $T_{\text {cap }}$ 


\section{Valve Model}

Mass flow through the ducting valve during inventory change was determined using equation (31) - (32)

$$
W=\sqrt{\frac{\Delta P \times \rho}{2 f\left(\frac{L}{D}\right)}}
$$

Mass flow rate

$$
\frac{d W}{d t}=W A
$$

\section{Sizing and weight model}

The inventory control system consists of the storage tank (ICT) and valves (ICV). For the purpose of this study, cylindrical pressure vessel was selected. This type of pressure vessel is generally preferred because they present simple manufacturing problem and better use of available space. To design the pressure vessel, ASME VIII code was used as reference guide (PDHOnline Course 2012). The ASME code design criteria consist of basic rules specifying the design method, load, allowable stress, acceptable materials and fabrication.

The pressure vessel was formed from cylindrical shells, two ellipsoidal head, saddle supports, valves and reinforcement, and an insulator perforated on the walls of the cylindrical shell (Frutschi 1979; Nieuwoudt 2003). The procedure for determining the optimum size and weight of the storage pressure vessel based on references (Moss 2004; Megyesy 1973) was as follow

First the tank capacity factor $\mathrm{F}$ was determined with equation (33)

$$
\begin{gathered}
F=\frac{P_{t \text { Design }}}{C \times S_{a} \times E}, \quad 0 \leq C \leq 0.125, \\
0.85 \leq E \leq 1
\end{gathered}
$$

$S_{a}$ is the stress value of tank material used (steel) Where

$$
P_{t \text { Design }}=\left(P_{5}+P_{t 1}\right) \times J
$$

Using the Value of $\mathrm{F}$ and Total Volume of Fluid in storage tank, the diameter D is obtained from reference (Moss 2004; Megyesy 1973; Osigwe, Pilidis, et al. 2018), and total length of pressure vessel storage tank is given by

$$
L=\frac{4 V_{T}}{\pi D^{2}}
$$

The thickness of the cylindrical shell $\left(C S T_{T}\right)$ is obtained as follows

$$
C S T_{T}=\frac{P_{t \text { Design }} \times r_{i}}{\left[S_{a} E-0.6 P_{t \text { Design }}\right]}+C
$$

The internal volume of the cylindrical shell $\left(\mathrm{V}_{\mathrm{cs}}\right)$ was then obtained as

$$
V_{c S}=\pi r_{i}^{2} h
$$

Where $r_{i}$ is the storage tank internal radius

The maximum allowable stress used to determine the minimum pressure vessel storage wall thickness was based on material properties from references (PDHOnline Course 2012; Moss 2004)

Similarly, the required thickness of the dished head ellipsoidal $\left(\mathrm{EH}_{\mathrm{T}}\right)$ was obtained by

$$
\begin{array}{r}
E H_{T}=\frac{P_{t \text { Design }} \times D \times K}{\left[2 S_{a} E-0.2 P_{t \text { Design }}\right]}+C, \\
K=\frac{\left[2+(D / 2 h)^{2}\right]}{6}
\end{array}
$$

Where $\mathrm{K}$ is the stress intensification factor Volume of the ellipsoidal $\left(\mathrm{V}_{\mathrm{e}}\right)$ was calculated as

$$
V_{e}=\frac{2 \pi r_{i}^{2}}{3}
$$

The total volume can be written in terms of ellipsoidal and cylindrical shell volume as

$$
V_{T}=V_{c s}+V_{e}
$$

Therefore, the insulator volume $\left(\mathrm{V}_{\mathrm{c}}\right)$ was obtained, since the internal volume is occupied by the perforated insulator

$$
V_{c}=V_{T}-\frac{w_{c}}{\rho_{c}}
$$

Having obtained the volume, the weight of the cylindrical shell was obtained from (Moss 2004)

$$
W_{C S}=\pi \times D \times C S T_{T} \times L \times \rho
$$

Weight of the ellipsoidal head $\left(\mathrm{W}_{\mathrm{EH}}\right)$ is given as (Moss 2004)

$$
W_{E H}=1.084 D^{2} \times E H_{T} \times \rho
$$

Weight of insulator $\left(\mathrm{W}_{\mathrm{c}}\right)$ is given as

$$
W_{C}=V_{T} \times H C_{\text {ratio }} \times \rho
$$

Therefore, the total weight of the Pressure vessel storage tank is given as

$$
\text { Total Weight } \text { ICS }=\left(W_{C S}+W_{E H}+W_{C}\right)
$$

The rated power and plant efficiency for the different working fluids used in this analysis was obtained from simulations in GT-ACYSS for the mass flow as shown in Table 1 based on characteristics shown in Table 2. The part-load operation was simulated to understand the impact of the different working fluids on the cycle performance taking into account the effect of Reynolds number. Also, during the part-load operation, there is a transfer of mass from the main gas turbine system to the inventory tank. Using the Eqs (19) to (45) modelled in GT-ACYSS, to analyze the effect of the selected working fluids on the inventory control level in terms of mass of the inventory tank, volume of the inventory and response rate of the valves, as the selected working fluid 
is transferred from the main cycle system to the inventory tank under part-load operations.

\section{CASE STUDY - ENGINE SYSTEM DESCRIPTION}

To set the objective of this paper, an intercooled-recuperated closed-cycle gas turbine was utilized in the analysis. The main design characteristics of the reference plant used in this study were based on the cycle shown in Fig (1). The cycle consist of a low-pressure compressor (LPC), intercooler (IC), high-pressure compressor (HPC), recuperator heat exchanger (RX), gas-heater $(\mathrm{GH})$, turbine, and a pre-cooler (PC). Both the LPC and HPC are driven on a single shaft. A summary of the plant characteristic is described in Table 1. The pressure rise from the HPC was utilized to ensure natural transfer of the working gas between the storage tank and the GT-cycle loop.

From the diagram presented in Fig.1, the ICVs refer to the inventory control valves. The valve lift of the ICVs is actuated by an output controller, which has an input signal of the difference between the nominal and actual power output. This variation triggers the opening and closing of the ICVs. Further explanation on the valve operation is discussed in reference (Osigwe 2018). The heat source temperature and mass flow was simulated the same for all working fluid and other plant characteristics as shown in Table 1. This is to give a reasonable comparison on the behavior of each selected working used in this analysis. However, in reality the maximum attainable temperature may differ for each working fluid.

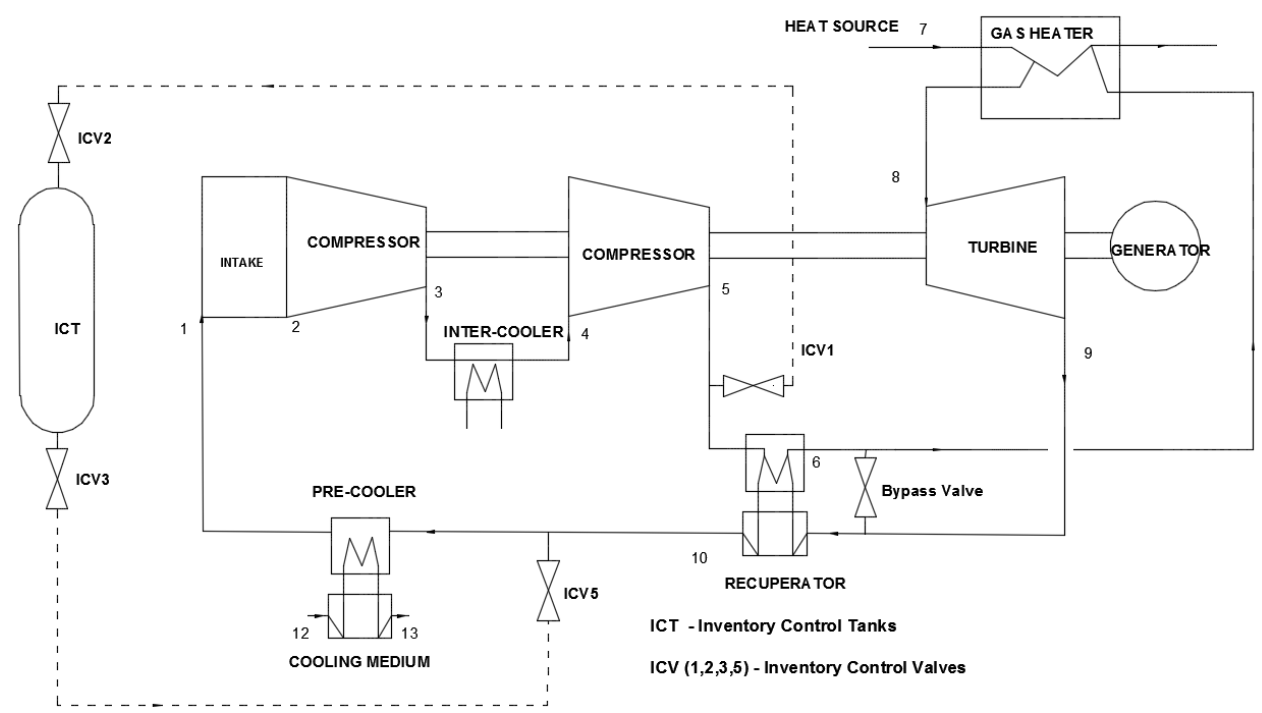

Figure 1 Schematic of Intercooled-Recuperated Closed-Cycle Gas Turbine Coupled Indirectly to a Nuclear Reactor

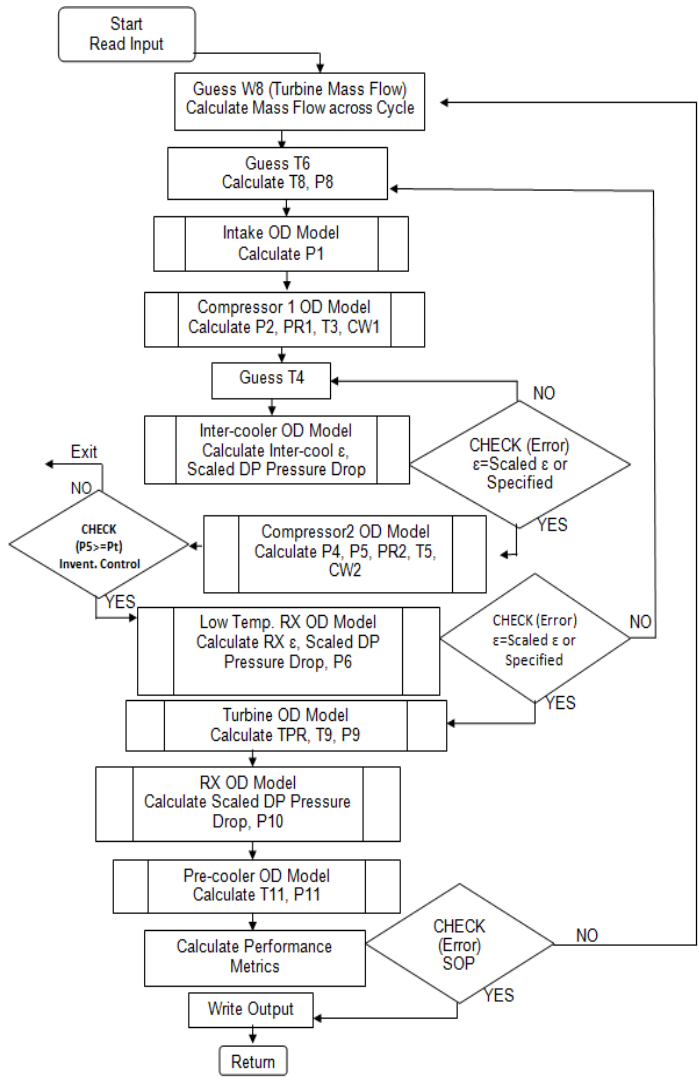

Table 1 Summary of Power Plant Design Point Description

\begin{tabular}{ll}
\hline \hline Description & Unit \\
Heat Source Temp. & $1100(\mathrm{~K})$ \\
LPC Pressure ratio & 1.65 \\
LPC Inlet Pressure & $8.2(\mathrm{~atm})$. \\
LPC Inlet Temperature & $290(\mathrm{~K})$ \\
HPC Pressure ratio & 2.40 \\
LPC\& HPC efficiency & $86(\%)$ \\
Turbine efficiency & $90(\%)$ \\
Flow rate at LPC & $230(\mathrm{~kg} / \mathrm{s})$ \\
IC effectiveness & $90(\%)$ \\
RX \& GH effectiveness & $90(\%)$ \\
Tank pressure & $8.2(\mathrm{~atm})$ \\
Initial tank volume & $2100 \mathrm{~m}^{3}$ \\
GT cycle volume & $1500 \mathrm{~m}^{3}$ \\
\hline \hline
\end{tabular}

Figure 2 Iterative Procedure for Cycle using Inventory Control Strategy 
Table 2 Simulated cycle performance at constant mass flow

\begin{tabular}{lll}
\hline \hline Working fluid & Simulated Power (MW) & Efficiency (\%) \\
Air & 40.8 & 41.2 \\
Carbon dioxide & 27.50 & 39.8 \\
Helium & 170.14 & 41.98 \\
Nitrogen & 43.28 & 41.5 \\
\hline \hline
\end{tabular}

\section{RESULTS AND DISCUSSION}

At first, the effect of Reynolds number on the cycle performance was analyzed for the different working fluids Reynolds number describes the relative importance of fluid resistance to flow. For any flow gas condition, this is reflected as the ratio of body forces (reflecting velocity and momentum effects) to viscous forces (causing frictional pressure losses (Wilson and Korakianitis 1998; Wassel 1968; Bullock 1964). As the working fluid moves out and into the gas turbine cycle loop, the resistance effect to flow could impact on the cycle performance.

Thus, the turbomachinery component efficiency correction is given by:

$$
\begin{gathered}
1-\eta_{\text {fluid }}=K\left[\text { Re }_{\text {fluid }}\right]^{-n} \\
n=0.2 \text { for } R e>0.45 * 10^{5}, n=0.5 \text { for } R e \\
<0.45 * 10^{5}
\end{gathered}
$$

Where Reynolds number is expressed as

$$
R e=\frac{\rho U_{m} L_{m}}{\mu}
$$

Where $\mathrm{U}_{\mathrm{m}}$ is the velocity, and $L_{m}$ is the characteristics length

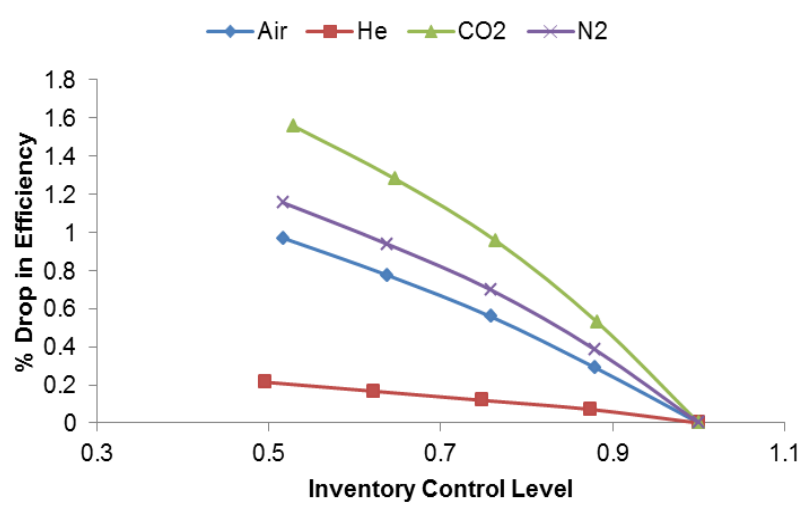

Figure 3 Effect of Reynolds number on cycle efficiency at part-load operation

As shown in Fig. 3, the effect of Reynolds number on the cycle performance is almost un-noticed for helium fluid with $0.2 \%$ drop in efficiency, while air had $0.9 \%$ drop, nitrogen $1.1 \%$ and carbon dioxide $1.5 \%$ drop in cycle efficiency at $50 \%$ part-load. These changes can be traced to the molecular weight and properties of the fluid. The drop in efficiency has an implication on the operational cost of the plant in terms of Reynolds number effect. However, there are other factors that could also contribute to the overall assessment of the operational cost, especially the cost of the working fluid. The cost of helium is almost five (5) times the cost carbon dioxide and about seven times the cost of nitrogen, which would add the operational cost since the working fluid in the loop is changed on an annual basis.

Based on the assumptions made for the initial volume of the inventory tank and gas turbine (GT) cycle loop, the initial mass of the inventory tank and the GT cycle before the start of part-load operation were obtained using Eqs (24). The result of the initial mass is shown in Fig. 4. Due to the molecular weight of helium, it gives an advantage for a compact inventory tank and GT cycle system design. Thus, this also have a direct effect on the capital cost of the plant. Also, assuming that the size of inventory tank is kept constant for all working fluids, it would imply that utilizing helium will accommodate more fluid volume compared with other working fluids used in this study. This would mean, that the ICS can be operated to accommodate more part-load operation (for example up to $30 \%$ low grid demand) without having a significant effect on the overall plant efficiency.

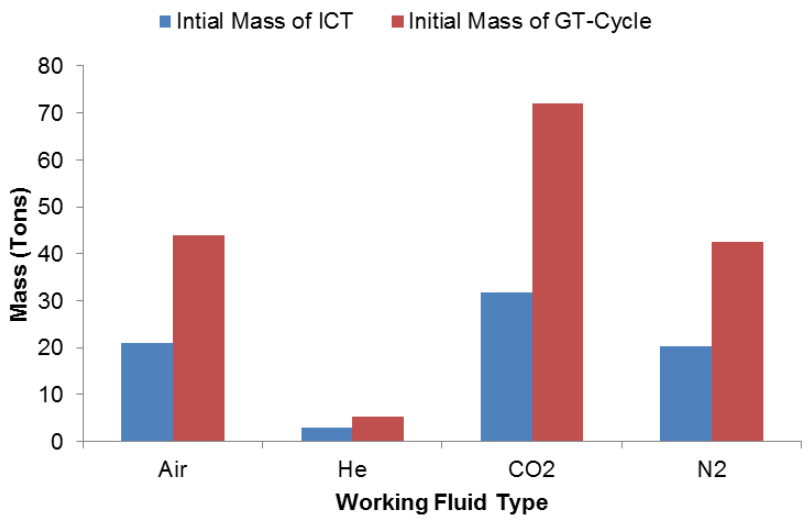

Figure 4 Mass of Inventory tank and GT cycle before part-load operations

During part-load operation, the working fluid in the GT cycle is transferred into the inventory control tank. Figure 5 shows the mass of fluid taken out from the GT cycle at the opening of inventory valves from $100 \%$ load to $50 \%$ load. Similarly, Fig. 6 describes the total mass of the inventory tank as the load requirement moves from full load to $50 \%$.

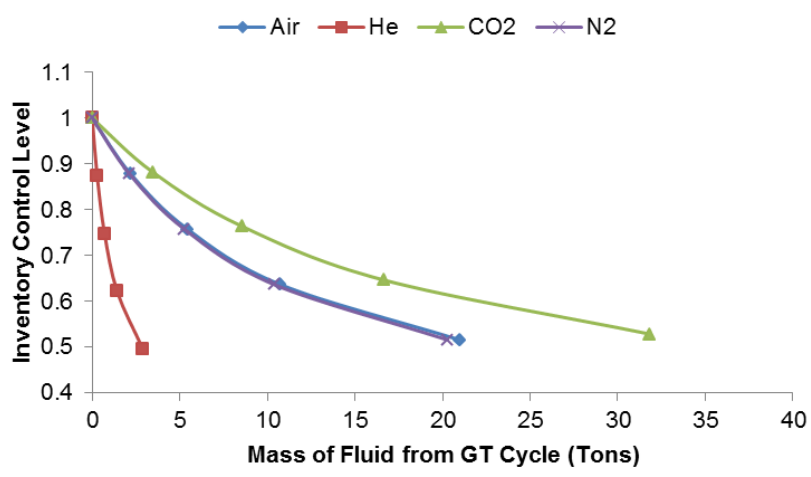

Figure 5 Mass of working fluid leaving the GT cycle during part-load operation 


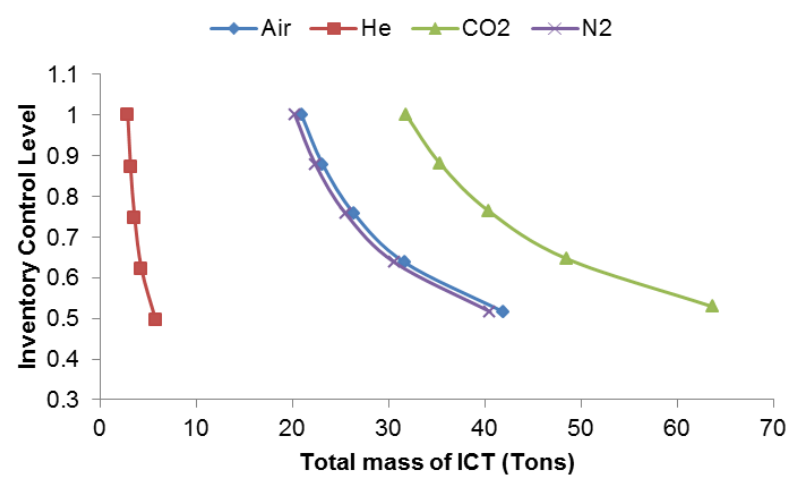

Figure 6 Total mass of ICT during part-load operation

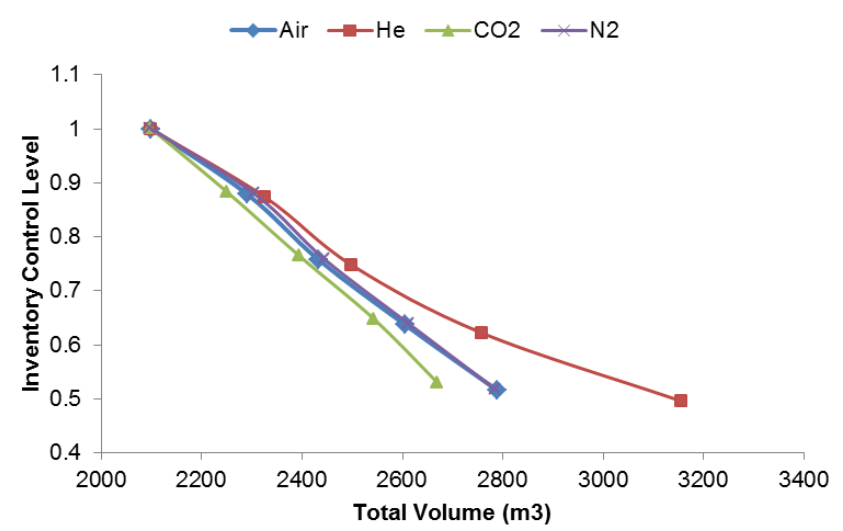

Figure 7 Total volume of inventory tank during part-load operation

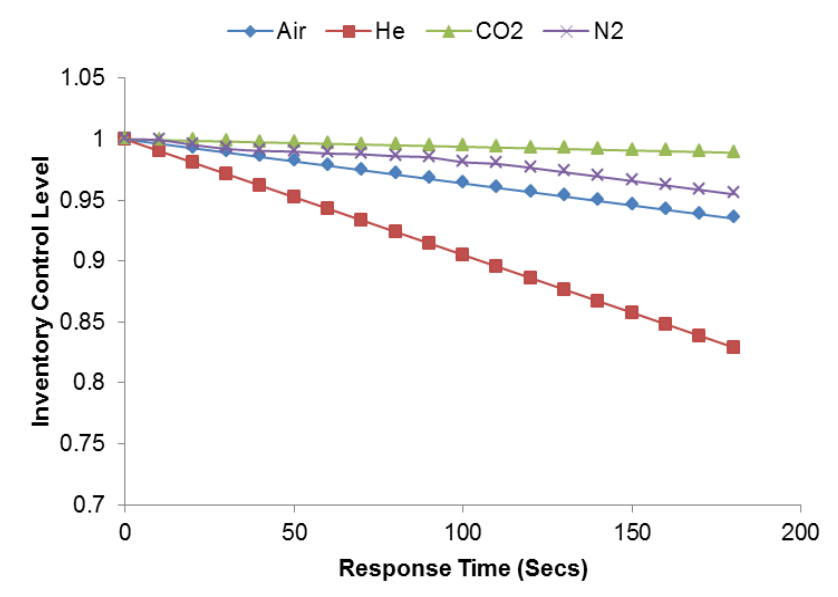

Figure 8 Working fluid responses to ICS part-load operation

Similarly, Fig.7 shows the total volume of the inventory tank at full load to $50 \%$ load. This implies that the level of the inventory control at part-load can be influenced by the working fluid for a fixed inventory tank size. In figure 8 , for a fixed valve diameter, the response rate of carbon dioxide was the least, as a result of its molecular weight. To increase the rate of response for carbon dioxide will require a larger valve size diameter, which means, an additional cost.
Although helium seems to show some reasonable advantage over other fluids, it is, however, necessary for a full economic assessment to be done to validate its viability.

\section{CONCLUSIONS}

The overarching results from this analysis can be concluded as follow

- The choice of working fluid in the closed-cycle gas turbine has an effect on the inventory control system and overall cycle performance due the thermodynamic and transport properties of the fluid.

- Helium seems to have an advantage over other working used in the analysis in terms of Reynolds effect and compact design (size and weight). This is due to its low molecular weight and high specific heat properties. However, the cost of helium could affect the investment decision of using it.

- For a fixed inventory tank size, helium would accommodate more fluid volume compared with other working fluids used in this study, which means that the ICS can be operated to accommodate more part-load operation (for example up to $30 \%$ low output power) without having a significant effect on the cycle performance because the effect of Reynolds number is almost un-noticed as the fluid moves from the GT-cycle into the tank. This is not the same for fluid like carbon dioxide

- For a fixed mass flow and a given heat source temperature, helium is almost five times greater in output power compared to air and nitrogen. Thus, comparing the ratio of the output power to the inventory tank volume of each working fluid in this study shows an advantage capacity for helium

\section{NOMENCLATURE}

A flow annulus area $\left(\mathrm{m}^{2}\right)$

C corrosion allowance

$C_{p} \quad$ specific heat at constant pressure

$C_{v} \quad$ specific heat at constant volume

$\mathrm{CH} \quad$ corrected enthalpy

CMF corrected mass flow

CW compressorwork

D diameter

E joint efficiency

$F \quad$ capacity factor

GT gas turbine

$H \quad$ enthalpy $(\mathrm{J} / \mathrm{kgK})$

HPC high pressure compressor

HST heat source temperature (reactor)

ICS inventory control system

ICT inventory control tank

ICV inventory control valve

$J \quad$ factor of safety

$K \quad$ stress intensification factor

$L \quad$ length $(m)$

LPC low pressure compressor

$M_{G T} \quad$ mass of gas turbine cycle loop

$M_{T} \quad$ mass of tank

$N \quad$ rotational speed ( $\mathrm{rpm})$ 


$\begin{array}{ll}P & \text { pressure }(\mathrm{Pa}) \\ P_{T} & \text { pressure of tank }(\mathrm{Pa}) \\ P R & \text { pressure ratio } \\ Q_{\text {actual }} & \text { actual heat transfer rate } \\ Q_{g} & \text { heat supplied from the nuclear reactor } \\ R & \text { specific gas constant }(\mathrm{J} / \mathrm{kgK}) \\ S_{a} & \text { stress value of tank material } \\ T & \text { temperature }(\mathrm{K}) \\ T_{\text {cap }} & \text { temperature of insulation in tank } \\ T W & \text { turbine work } \\ V & \text { velocity }(\mathrm{m} / \mathrm{s}) \\ V_{T} & \text { volume of tank }\left(\mathrm{m}^{3}\right) \\ W & \text { mass flow }(\mathrm{kg} / \mathrm{s})\end{array}$

\section{Greek letters}

$\begin{array}{ll}\rho & \text { density }\left(\mathrm{kg} / \mathrm{m}^{3}\right) \\ \gamma & \text { ratio of specific heats } \\ \delta & \text { referred pressure parameter } \\ \theta & \text { referred temperature parameter } \\ \eta & \text { efficiency } \\ \mu & \text { viscosity }\left(\mathrm{Ns} / \mathrm{m}^{2}\right) \\ \varepsilon & \text { effectiveness } \\ f & \text { friction factor } \\ \Delta & \text { difference } \\ \Omega & \text { inventory control range }\end{array}$

$\begin{array}{ll}\text { Subscripts } \\ 1-13 & \text { engine station number } \\ c & \text { compressor } \\ c_{\text {in }} & \text { compressor inlet } \\ c_{\text {out }} & \text { compressor outlet } \\ t & \text { turbine, tank } \\ t_{\text {in }} & \text { turbine in } \\ t_{\text {out }} & \text { turbine out }\end{array}$

\section{REFERENCES}

Abram, T, and S Ion. 2008. "Generation-IV Nuclear Power: A Review of the State of the Science." Energy Policy 36: 4323-30. doi:10.1016/j.enpol.2008.09.059.

Albright, J, E. A Liese, S Zitney, P Mahapatra, and D Bhattacharyya. 2017. "Load-Following Control for a 10 MWe Supercritical CO2 Recompression Brayton Power." In 2017 AIChE Annual Meeting. Minneapolis: AIChE.

Bammert, K., and G Krey. 1971. "Dynamic Behavior and Control of Single-Shaft Closed-Cycle Gas Turbines." In Gas Turbine Conference and Products Show, 44753. Houston, Texas: Transactions of ASME, Journal of Engineering Power.

Berchtold, M, and C Keller. 1962. Transfer of the Working Medium in the Working Medium Exchange between a Closed-Cycle Gas Turbine Plant and a Reservoir. 3218807 , issued 1962.

Bitsch, D., and J Chaboseau. 1970. "Power Level Control of a Closed Loop Gas Turbine by Natural Transfer of Gas between the Loop and Auxilliary Tanks." In BNES-Conference. London: BNES.

Botha, B. W., and P. G. Rousseau. 2007. "Control Options for Load Rejection in a Three-Shaft Closed Cycle Gas Turbine Power Plant." Transactions of the ASME 129: 806-13.

Bullock, R. O. 1964. "Analysis of Renolds Number and Scale Effects on Performance of Turbomachinery." Journal of Engineering for Gas Turbines and Power, 247-55.

Covert, R. E., G. Krase, and D. C. Morse. 1974. "Effect of Various Contol Modes on the Steady-State Full and Part Load Performance of a Direct-Cycle Nuclear Gas Turbine Power Plant." ASME, no. 74-WA/GT-7: 1-9.

Decher, R. 1994. Energy Conversion Systems, Flow Physics and Engineering. Oxford: Oxford University Press.

El-genk, Mohamed S, and Jean-michel Tournier. 2009. "Performance Analyses of VHTR Plants with Direct and Indirect Closed Brayton Cycles and Different Working Fluids." Progress in Nuclear Energy 51: 556-72. doi:10.1016/j.pnucene.2008.11.004.

Forum Generation IV International. 2014. "Technology Roadmap Update for Generation IV Nuclear Energy Systems." Washinghton D.C.

Frutschi, H. U. 1979. Method for Regulating the Power Output of a Thermodynamic System Operating on a Closed Gas Cycle and Apparatus for Carrying out the Method. 4148191, issued 1979.

Frutschi, H U. 2005. Closed-Cycle Gas Turbines: Operating Experience and Future Potential. 1st ed. New York: ASME.

Gad-Briggs, A, P. Pilidis, and T Nikolaidis. 2017. "Analyses of the Control System Strategies and Methodology for Part Power Control of the Simple and Intercooled Recuperated Brayton Helium Gas Turbine Cycles for Generation IV Nuclear Power Plants." ASME Journal of Nuclear Engineering and Radiation Science 3 (4). doi:10.1115/1.4036737.

Gad-Briggs, A, P. Pilidis, and T Nikolaidis. 2017. "Analyses of the Load Following Capabilities of Brayton Helium Gas Turbine Cycles for Generation IV Nuclear Power Plants." ASME Journal of Nuclear Engineering and Radiation Science 3 (4). doi:10.1115/1.4036983.

Invernizzi, C. M. 2017. "Prospects of Mixtures as Working Fluids in Real-Gas Brayton Cycles.” Energies 10: 115. doi:10.3390/en10101649.

Kakac, S, and H Liu. 2002. Heat Exchangers Selection, Rating and Therrmal Design. 2nd ed. New York: CPC Press.

Kelly, J. E. 2014. "Generation IV International Forum: A Decade of Progress through International Cooperation." Progress in Nuclear Energy 77: 240-46.

Lee, J C, Jr J. Campbell, and D E Wright. 1981. "Closed-Cycle Gas Turbine Working Fluids." Transactions of the ASME Vol. 103: 220-28.

Locatelli, G., S Boarin, F Pellegrino, and M. E Ricotti. 2015. "Load Following with Small Modular Reactors (SMR): A Real Options Analysis.” Energy 80: 41-54. doi:10.1016/j.energy.2014.11.040.

Locatelli, G., M. Mancini, and N Todeschini. 2013. "Generation IV Nuclear Reactors: Current Status and Future Prospects.” Energy Policy 61: 1503-20.

Matimba, T. A. D., D. L. W Krueger, and E. H Mathews. 
2007. “A Multi-Tank Storage Facility to Effect Power Control in the PMBR Power Cycle." Nuclear Engineering and Design 237: 153-60.

Megyesy, E. F. 1973. Pressure Vessel Handbook. 12th ed. Tulsa, Oklahoma: Pressure Vessel Publishing.

Moss, D. 2004. Pressure Vessel Design Manual. 3rd ed. Oxford: Gulf Professional Publishing.

Munoz de Escalona, J. M., D. Sanchez, R. Chacartegui, and T. Sanchez. 2013. "Performance Analysis of Hybrid Systems Incorporating High Temperature Fuell Cells and Closed Cycle Heat Engines at Part Load Operations." International Journal of Hydrogen Energy 38: 570-78.

Nieuwoudt, C. 2003. "Helium Tank Management Model - A Report to Determine Tank Sizes." Pretoria, South Africa.

Olumayegun, O., M. Wang, and G. Kelsall. 2016. "Closed-Cycle Gas Turbine for Power Generation: A State-of-the-Art Review.” Fuel 180: 694-717. doi:10.1016/j.fuel.2016.04.074.

Osigwe, E. O. 2018. "Techno-Economic and Risk Analysis of Closed-Cycle Gas Turbine Systems for Sustainable Energy Conversion." PhD Thesis, Cranfield University.

Osigwe, E. O., A Gad-Briggs, T Nikoliadis, P. Pilidis, and S. Sampath. 2018. "Performance Analysis of Generation IV Nuclear Reactor Power Plant Using CO2 and N2: Case Study of a Recuperated Brayton Gas Turbine Cycle." In Proceedings of the 2018 26th International Conference on Nuclear Engineering. London: ASME. doi:10.1115/ICONE26-81337.

Osigwe, E. O., P. Pilidis, S. Sampath, T Nikolaidis, and M Obhuo. 2018. "Techno-Economic Study of Inventory Control Startegy for a Single-Shaft Intercooled-Recuperated Closed-Cycle Gas Turbine." Working Article, Cranfield University.

Osigwe, E. O, A Gad-Briggs, T Nikolaidis, P. Pilidis, and S. Sampath. 2018. "Multi-Fluid Gas Turbine Components Scaling for a Generation IV Nuclear
Power Plant Performance Simulation." In Proceedings of the 2018 26th International Conference on Nuclear Engineering. London: ASME. doi:10.1115/ICONE26-82373.

Osigwe, E. O, P Pilidis, T Nikoliadis, and S Sampath. 2017. "GT-ACYSS: Gas Turbine Arekret-Cycle Simulation Tool for Training and Educational Purposes." Working Article, Cranfield University.

PDHOnline Course. 2012. "ASME Section I \& Section VIII Fundamentals."

Robinson, S.T. 1957. "Influence of Working-Fluid Charateristics on the Design of the Closed-Cycle Gas Turbine." ASME 95 (2469): 427-28. doi:10.1126/science.95.2469.427-b.

Shah, R. K, and D.P Sekulic. 2003. Fundamentals of Heat Exchanger Design. New Jersey: John Wiley \& Sons, Inc.

Singh, R., M. P Kearney, and C Manzie. 2013. "Extremum-Seeking Control of a Supercritical Carbon-Dioxide Closed Brayton Cycle in a Direct-Heated Solar Thermal Power Plant." Energy 60: 380-87. doi:10.1016/j.energy.2013.08.001.

Ulizar Alvarez., J. I. 1998. "Simulation of Multi Fluid Gas Turbines." PhD Thesis, Cranfield University. http://hdl.handle.net/1826/3537.

Wang, Jie, and Yihua Gu. 2005. "Parametric Studies on Different Gas Turbine Cycles for a High Temperature Gas-Cooled Reactor" 235: 1761-72. doi:10.1016/j.nucengdes.2005.02.007.

Wassel, A. B. 1968. "Reynolds Number Effects in Axial Compressors." ASME Journal of Engineering for Gas Turbines and Power, 149-56.

Wilson, D. G, and T Korakianitis. 1998. The Design of High-Efficiency Turbomachinery and Gas Turbine. 2nd ed. New Jersey: Prentice Hall. 


\section{Inventory control systems for nuclear powered closed-cycle gas turbine: technical studies on effect of working fluid options}

Osigwe, Emmanuel O.

Unknown

Osigwe EO, Gad-Briggs A, Pilidis P, et al., (2019) Inventory control systems for nuclear powered closed-cycle gas turbine: technical studies on effect of working fluid options. In: ICONE-27: 27th International Conference on Nuclear Engineering, 19-24 May 2019, Ibaraki, Japan https://doi.org/10.1299/jsmeicone.2019.27.2085 Downloaded from Cranfield Library Services E-Repository 